\title{
SEDIMENTAÇÃO DE LEALDADES PARTIDÁRIAS NO BRASIL: Tendências e descompassos
}

\section{André Marenco dos Santos}

Interpretações sobre a consistência dos partidos políticos brasileiros parecem obedecer a um padrão cíclico, enfatizando evidências ora de fragilidade, ora de consolidação das organizações partidárias nacionais. As primeiras incursões analíticas sobre o tema, a partir dos anos 60 , foram marcadas pelo diagnóstico do subdesenvolvimento partidário, produto de resíduos de relações tradicionais na sociedade brasileira, traduzidos na forma de clientelismo e controle oligárquico do voto. Em versão mais sofisticada, Soares (1973) chamava a atenção para as conseqüências do isolamento de zonas rurais, em contraste com a afluência social e cultural das regiões urbanas, destacando o impacto dos processos de urbanização e sua influência sobre a dinâmica partidária, expressos no crescimento do PTB e da UDN urbana e ideológica, paralelo ao declínio do PSD.

Uma virada na discussão foi provocada pela ênfase institucional, especialmente a partir do trabalho de Maria do Carmo Campello de Souza (1990 [1976]). A centralização da máquina administrativa, prévia à expansão da competição eleitoral, teria inibido a aptidão governativa dos partidos, convertidos em prolongamentos da burocracia estatal. Mais recentemente, Mainwaring (1991 e 1999;
Mainwaring e Liñan, 1998) reforçou o diagnóstico das mazelas do sistema partidário brasileiro isolando as conseqüências das regras eleitorais, e especialmente do procedimento de lista aberta, sobre a formação de lealdades intrapartidárias.

Nova virada no rumo da investigação sobre os partidos brasileiros foi provocada pelo aparecimento de um conjunto de trabalhos com inclinação para uma "avaliação positiva" da organização partidária nacional. A tendência à consolidação do sistema partidário, no início dos anos 60, revelada por Lavareda (1991), a disciplina partidária nas votações legislativas mostrada pela pesquisa de Figueiredo e Limongi (1995 e 1999), a relevância da atividade governamental exercida pelos partidos durante o período 1985-1997 (Meneguello, 1998), a dimensão (Nicolau, 1996) e os custos da migração partidária (Schmitt, 1999) convergiram para uma mudança no tratamento conferido aos partidos brasileiros, vistos agora pelo prisma de sua afirmação.

O forte contraste entre abordagens concorrentes, que adotam a fragilidade ou, alternativamente, a consistência do sistema partidário, poderia sugerir tratar-se de recortes temporais ou geográficos distintos, privilegiados em cada empreita- 
da analítica. Contudo, a discrepância entre os diferentes diagnósticos pode revelar pistas sugestivas sobre o grau de maturação do sistema de partidos no Brasil. Se, à luz das descobertas mais recentes, não parece mais válido repetir o senso comum sobre a falta de partidos no Brasil, concluir pela presença de organizações estáveis e homogêneas talvez soe prematuro. Assim, não se trata de fazer uma opção entre um ou outro juizzo, mas de descobrir os sinais contraditórios de um processo que parece ainda inconcluso e incerto.

Sintomas da presença de organizações partidárias institucionalizadas podem ser isolados quando estas se convertem em parâmetro para a conduta de seus membros e seguidores. Estabilidade nos resultados eleitorais, disciplina nas decisões legislativas e continuidade nas carreiras políticas são indicadores de que as organizações partidárias foram capazes de controlar a oferta de representação política, adquirindo condição de oligopólio neste terreno. O problema consiste em que estes três vetores não convergem, de forma necessária e simultânea, em direção e sentido. A experiência uruguaia é sugestiva a respeito: baixa volatilidade eleitoral, acompanhada por forte disputa intrapartidos, coalizões suprapartidárias nas votações legislativas e instabilidade nas carreiras políticas (Gonzalez, 1993; Botttinelli, 1993 ).

Todo este processo torna-se ainda mais complexo, adquirindo contornos de um mosaico, em decorrência da estrutura federativa do Estado brasileiro. Unidades subnacionais possuem tradições e formatos de competição próprios (Lima Jr., 1983), configurando distintas estruturas de oportunidade para a mobilidade na carreira política. A operação que consiste em agregar representações estaduais sob rótulos partidários nacionais chega aos limites de uma federação de seções estaduais (Panebianco, 1990), ao menos até que o tempo possa produzir seus efeitos, formando bancadas treinadas e experimentadas em funções partidárias e legislativas nacionais.

Sobre os partidos brasileiros, sabe-se hoje que possuem alta disciplina nas votações legislativas. Mas, ao mesmo tempo, não se pode negligenciar que apresentam lealdades incertas, evidenciadas pelo fenômeno de intensa migração interparti- dária. Defasagem que pode tornar-se inteligível à luz da distinção, apontada na literatura sobre partidos, entre disciplina e coesão partidárias (Bowler, Farrell e Katz, 1999; Figueiredo e Limongi, 1999).

Um rastreamento dos vínculos partidários firmados pelos parlamentares ao longo de suas carreiras permite estimar a durabilidade e consistência dos laços de lealdade intrapartidários, bem como a homogeneidade de cada bancada. Em circunstâncias nas quais as organizações partidárias são os principais fornecedores dos insumos necessários para a arregimentação eleitoral (eleitores fiéis, bandeiras políticas, pessoal de apoio, finanças), ou quando estes não podem ser obtidos junto a outras fontes, aspirantes à carreira parlamentar terão incentivos para permanecer fiéis às suas estruturas, sendo premiados por sua lealdade com a investidura eleitoral. O quanto as oportunidades de carreira são efetivamente controladas por organizações partidárias condiciona as estratégias de indivíduos que aspiram à profissionalização política.

A análise empreendida aqui pretende avaliar a relevância das lealdades partidárias para as carreiras políticas dos deputados brasileiros. Para isto, buscou-se identificar as filiações partidárias firmadas pelos parlamentares ao longo de suas trajetórias políticas, ${ }^{1}$ os diferentes trânsitos interpartidários observados em cada organização, e, finalmente, procurou-se captar tendências à sedimentação de lealdades organizacionais. O exame concentrou-se nos dois ciclos pluripartidários, descartando as legislaturas bipartidárias do regime autoritário, uma vez que, nestas, estes movimentos individuais estavam constritos por barreiras políticas e de legislação eleitoral.

\section{Lealdades partidárias no primeiro sistema pluripartidário (1946-1962)}

Parte expressiva dos diagnósticos produzidos sobre o sistema partidário vigente entre 1946 e 1962 identificou um processo de desintegração em curso, representado pela multiplicação de legendas, aleatoriedade na fabricação das coalizões e o fracionamento do voto, tendências exacerbadas nas derradeiras legislaturas antes do colapso de- 
mocrático (Schwartzman, 1988). Outra parte percebeu nos movimentos eleitorais uma direção inteligível, interpretando este processo como resultado de um realinhamento eleitoral beneficiando o Partido Trabalhista Brasileiro (PTB) e as pequenas legendas, em prejuízo dos partidos conservadores, em especial o Partido Social Democrático (PSD) (Soares, 1973; Campello de Souza, 1990).

Parece revelador, assim, verificar os efeitos de um quadro que, no plano federal, apresentava movimentos instáveis e irregulares sob as fronteiras partidárias, especialmente com referência à fidelidade aos vínculos partidários em cada organização.
Em particular, trata-se de observar se a expansão do PTB e das pequenas legendas foi capaz de exercer atração sobre candidatos egressos de outras agremiações e, ao mesmo tempo, de identificar a migração de parlamentares de siglas em declínio (PSD, UDN) para outras alternativas eleitorais.

O primeiro passo neste sentido consistiu em um exame das bancadas partidárias sob o prisma de sua homogeneidade com relação às lealdades firmadas. Para isto, identificou-se a proporção de deputados com filiações exclusivas - ou seja, com apenas um registro partidário — na legenda responsável por sua eleição.

Tabela 1

Antecedentes Partidários (1950-1962)*

$(\mathrm{em} \%)$

\begin{tabular}{|c|c|c|c|c|c|c|c|c|c|}
\hline \multicolumn{2}{|c|}{ Partido } & \multicolumn{8}{|c|}{ Filiações Anteriores } \\
\hline & & PSD & UDN & & PPC & PSP & PTB & & PPT \\
\hline \multirow[t]{4}{*}{ PSD } & 62 & 93,7 & 1,6 & & 7,6 & 1,6 & - & & 0,8 \\
\hline & 58 & 87,4 & 1,8 & & 2,7 & 3,6 & 0,9 & & 2,7 \\
\hline & 54 & 86,7 & 1,6 & & 4,1 & 2,5 & 2,5 & & 1,6 \\
\hline & 50 & 93,5 & 0,9 & & 1,8 & 0,9 & 1,8 & & 0,9 \\
\hline \multirow[t]{4}{*}{ UDN } & 62 & 1,1 & 93,4 & & 1,4 & - & - & & 2,2 \\
\hline & 58 & - & 93,7 & & 2,8 & - & 1,4 & & - \\
\hline & 54 & - & 91,1 & & 3,9 & 1,3 & - & & 3,4 \\
\hline & 50 & - & 96,0 & & 1,3 & 1,3 & 1,3 & & 1,3 \\
\hline \multirow[t]{4}{*}{$\mathrm{PPC}^{2}$} & 62 & 2,6 & 5,3 & - & 89,5 & 3,3 & - & & 2,6 \\
\hline & 58 & 5,9 & 2,9 & 8,8 & 79,4 & 5,8 & 2,9 & & - \\
\hline & 54 & 10,0 & 16,7 & - & 70,0 & - & 3,3 & & - \\
\hline & 50 & 4,3 & 8,7 & - & 87,0 & - & - & & - \\
\hline \multirow[t]{4}{*}{ PSP } & 62 & 21,7 & 8,6 & & - & 69,6 & 4,3 & & 4,3 \\
\hline & 58 & 4,5 & - & & 9,0 & 72,2 & 13,6 & & 4,5 \\
\hline & 54 & 10,7 & 7,1 & & - & 64,3 & 10,7 & & 7,1 \\
\hline & 50 & 27,8 & - & & - & 66,6 & 5,6 & & - \\
\hline \multirow[t]{4}{*}{ РTB } & 62 & 1,8 & 3,7 & & - & 1,8 & 89,7 & & 4,6 \\
\hline & 58 & 4,5 & 4,5 & & 4,5 & 1,5 & 79,1 & & 9,0 \\
\hline & 54 & 6,8 & 1,7 & & 1,7 & 1,7 & 84,5 & & 3,4 \\
\hline & 50 & 1,9 & 5,7 & & 1,9 & - & 90,6 & & - \\
\hline \multirow[t]{4}{*}{$\mathrm{PPP}^{3}$} & 62 & 12,9 & 3,2 & & 6,5 & 3,2 & 3,2 & 9,6 & 67,7 \\
\hline & 58 & 7,7 & 15,4 & & - & - & 15,4 & 23,1 & 61,5 \\
\hline & 54 & 9,1 & 9,1 & & - & 18,2 & 9,1 & - & 63,6 \\
\hline & 50 & 27,3 & - & & - & - & 18,2 & - & 54,5 \\
\hline
\end{tabular}

* As células sombreadas representam a porcentagem de deputados em cada bancada com filiação exclusiva à legenda responsável por sua eleição.

A soma das linhas pode ultrapassar 100, uma vez que é possível um parlamentar ter sido filiado a duas ou mais legendas. Fonte: "Câmara dos Deputados", Dicionário histórico-biográfico brasileiro (FGV-Cpdoc, 1984). 
Os dados da Tabela 1 permitem duas inferências: sobre a homogeneidade de cada bancada e sobre a eventual decomposição do sistema partidário, que se deveria revelar na forma de uma dispersão, traduzida em um número expressivo de parlamentares saídos das maiores agremiações passando a integrar outras bancadas no final do período.

As três grandes forças partidárias deste ciclo político, o PSD, o PTB e a União Democrática Nacional (UDN), apresentam bancadas acentuadamente homogêneas. Na UDN observa-se um fenômeno muito marginal de cooptação externa. Os forasteiros no PSD eram poucos, e na sua maioria oriundos das pequenas legendas conservadoras, indicando um movimento de compactação - e não dispersão - partidária. Por outro lado, em 1962, quando alcança seu melhor desempenho na disputa por cadeiras na Câmara dos Deputados, o PTB apresentava uma forte composição de petebistas exclusivos: apenas 10,3\% dos candidatos eleitos pelo partido traziam em seus currículos a história de um rompimento anterior com a(s) legenda(s) de origem - fenômeno residual, localizado principalmente em estados como Ceará, Alagoas, Rio Grande do Norte e Sergipe, onde o partido conheceu impulso significativo. Suas seções mais tradicionais e importantes (Rio Grande do Sul, Paraná, São Paulo e Pernambuco) apresentavam um recrutamento marcadamente interno, que atingia 96\% dos parlamentares eleitos pela sigla nestas circunscrições eleitorais.

O impacto produzido pela adesão de forasteiros adquire maiores proporções no Partido Social Progressista (PSP). Contudo, há certa consistência nestas transferências, originárias em sua maioria do PSD, percurso sem grande distância ideológica a ser vencida. Pode-se afirmar que o PSP constituiu-se, em alguns estados, em uma espécie de sublegenda para o PSD, assim como os pequenos partidos conservadores o foram para a UDN. Por outro lado, os pequenos partidos trabalhistas apresentavam uma composição mais inconsistente. Não só pela dimensão do recrutamento externo às fronteiras de cada organização, como também pela diversidade de origens partidárias de seus integrantes.

Em paralelo, pode-se inverter o ângulo de observação e buscar dimensionar a importância de deputados infiéis em cada momento. Considerando a legislatura derradeira de 1962, e procurando identificar a presença de deputados originários das três principais agremiações (PSD, UDN, PTB) e que agora estariam registrados por outras legendas (PSP, pequenos partidos), chega-se a uma proporção de 6,3\% da Câmara eleita naquele ano. Ocorrência de dimensões modestas, quando se esperam sinais de uma decomposição partidária. Seria de se esperar, inversamente, que esta se revelasse sob a forma de dispersão, com importante contingente de parlamentares egressos dos maiores partidos eleitos agora por pequenas legendas. Sua não ocorrência sugere uma estrutura de oportunidades para carreiras políticas com poucos incentivos para trocas de legendas, e um custo ainda importante associado à rejeição de lealdades firmadas.

\section{A dimensão das migrações no segundo sistema pluripartidário (1982-1998)}

Em contraste, o sistema partidário configurado após a redemocratização apresenta uma tendência para o incremento no trânsito interpartidário, conforme pode ser constatado na Tabela 2 .

O tempo deveria constituir um fator de rotinização partidária, contribuindo para dissolver o impacto de ondas migratórias produzidas por reacomodações políticas contextuais, como a Assembléia Constituinte ou eleições majoritárias. Seria de se esperar, também, que favorecesse o surgimento de gerações endógenas, especialmente nas novas agremiações (PFL, PSDB), formadas no curso da competição política. Contudo, não é isto que se observa quando se examina a distribuição de filiações exclusivas segundo cada bancada partidária. Chama a atenção, em particular, a pronunciada curva declinante da proporção de deputados com trajetória exclusiva por um único partido apresentada pela legislatura eleita em 1998.

O Partido da Frente Liberal (PFL) chegou a apresentar, entre 1986 e 1994, uma gradativa progressão no grupo de parlamentares saídos exclusivamente de suas fileiras. Formado como uma dissidência do PDS, seria esperado que suas ban- 
Tabela 2

Antecedentes Partidários (1986-1998)*

$(\mathrm{em} \%)$

\begin{tabular}{|c|c|c|c|c|c|c|c|c|c|c|c|c|}
\hline \multicolumn{3}{|c|}{ Partido } & \multicolumn{10}{|c|}{ Filiações anteriores } \\
\hline & & PDS & PFL & PTB & & PPC & PMDB & PSDB & PDT & PT & & PPE \\
\hline \multirow[t]{4}{*}{ PDS } & 98 & 33,3 & 23,4 & 10,0 & & 20,1 & 16,1 & 8,4 & 3,3 & - & & - \\
\hline & 94 & 72,5 & 13,7 & 4,0 & & 23,6 & 9,8 & 2,0 & - & - & & - \\
\hline & 90 & 83,3 & 2,4 & 9,6 & & 9,5 & 9,6 & - & 4,8 & - & & - \\
\hline & 86 & 100 & - & - & & - & - & - & - & - & & - \\
\hline \multirow[t]{4}{*}{ PFL } & 98 & 50,5 & 24,8 & 6,7 & & 23,2 & 13,4 & 1,0 & 1,9 & - & & 2,0 \\
\hline & 94 & 47,7 & 42,0 & 3,4 & & 11,2 & 3,4 & 1,1 & - & - & & - \\
\hline & 90 & 57,8 & 37,6 & 2,4 & & 9,5 & 7,1 & - & 1,2 & - & & 1,2 \\
\hline & 86 & 68,6 & 29,7 & - & & - & 1,7 & - & - & - & & - \\
\hline \multirow[t]{4}{*}{ РТВ } & 98 & 22,6 & 12,9 & 22,6 & & 25,8 & 38,7 & 3,2 & 12,9 & - & & - \\
\hline & 94 & 16,1 & 6,4 & 64,5 & & 6,5 & 12,9 & - & 3,2 & - & & - \\
\hline & 90 & 17,2 & 17,1 & 65,7 & & 20,0 & 17,2 & - & - & - & & - \\
\hline & 86 & 5,9 & - & 92,1 & & - & - & - & - & - & & - \\
\hline \multirow[t]{4}{*}{$\mathrm{PPC}^{4}$} & 98 & 30,7 & 23,9 & - & 52,0 & 10 & 42,9 & 4,8 & 4,8 & - & & - \\
\hline & 94 & 16,1 & 19,3 & 3,2 & 20,9 & 35,5 & 24,2 & 3,2 & 3,2 & - & & - \\
\hline & 90 & 41,1 & 25,3 & 6,4 & 5,3 & 41,1 & 34,7 & 3,2 & 3,2 & - & & 1,1 \\
\hline & 86 & 25,0 & - & - & - & 75,0 & - & - & - & - & & - \\
\hline \multirow[t]{4}{*}{ PMDB } & 98 & 17,3 & 8,5 & 2,4 & & 18,2 & 61,3 & 4,8 & 3,6 & - & & 1,2 \\
\hline & 94 & 5,6 & 3,7 & - & & 4,6 & 87,9 & - & 0,9 & - & & - \\
\hline & 90 & 11,9 & 3,6 & 3,7 & & 9,1 & 83,5 & 3,7 & - & - & & 0,9 \\
\hline & 86 & 8,8 & - & - & & - & 90,8 & - & - & 0,4 & & - \\
\hline \multirow[t]{4}{*}{ PSDB } & 98 & 19,2 & 14,1 & 11,1 & & 16,2 & 45,4 & 22,2 & 5,0 & 2,0 & & 7,0 \\
\hline & 94 & 6,2 & 6,3 & 4,7 & & 3,1 & 29,7 & 51,6 & 3,1 & - & & - \\
\hline & 90 & 10,8 & 13,5 & - & & 8,1 & 56,7 & 54,1 & 2,7 & - & & 2,7 \\
\hline & 86 & - & - & - & & - & - & - & - & - & & - \\
\hline \multirow[t]{4}{*}{ PDT } & 98 & 8,0 & 4,0 & 4,0 & & 8,0 & 32,0 & - & 52,0 & - & & 4,0 \\
\hline & 94 & - & 17,2 & - & & 5,8 & 17,2 & - & 64,7 & - & & - \\
\hline & 90 & 10,9 & 2,2 & - & & 4,2 & 21,8 & 2,2 & 73,9 & 4,3 & & 10,9 \\
\hline & 86 & - & - & - & & - & 4,2 & - & 83,3 & - & & - \\
\hline \multirow[t]{4}{*}{ PT } & 98 & - & - & - & & - & 5,1 & 1,7 & 1,7 & 88,1 & & 5,1 \\
\hline & 94 & - & - & - & & - & 6,1 & 2,0 & 2,0 & 89,8 & & 2,0 \\
\hline & 90 & - & - & - & & - & - & - & 2,7 & 97,1 & & 8,7 \\
\hline & 86 & - & - & - & & - & - & - & - & 100 & & - \\
\hline \multirow[t]{4}{*}{$\mathrm{PPE}^{5}$} & 98 & 6,8 & 6,8 & 6,8 & & - & 31,0 & 3,4 & 3,4 & - & 10,3 & 48,3 \\
\hline & 94 & - & - & 3,7 & & 7,4 & 29,6 & 3,7 & 11,1 & - & 3,7 & 51,9 \\
\hline & 90 & - & - & - & & - & 57,9 & 15,9 & 5,3 & 5,3 & - & 89,5 \\
\hline & 86 & - & - & - & & - & 71,4 & - & - & - & - & 28,6 \\
\hline
\end{tabular}

* As células sombreadas representam a porcentagem de deputados em cada bancada com filiação exclusiva à legenda responsável por sua eleição.

A soma das linhas pode ultrapassar 100, uma vez que é possível um parlamentar ter sido filiado a duas ou mais legendas.

Fonte: "Câmara dos Deputados", Dicionário bistórico-biográfico brasileiro (FGV-Cpdoc, 1984).

cadas apresentassem uma proporção elevada de representantes com antecedentes por aquele partido. Gradativamente, porém, estes foram sendo substituídos por parlamentares sem vínculos anteriores com outras legendas, projetados dentro da própria agremiação, tendência interrompida em 1998 pelo afluxo de novos migrantes, originários principalmente de outras siglas conservadoras.

O Partido da Social Democracia Brasileira (PSDB), o Partido Trabalhista Brasileiro (PTB) e os 
pequenos partidos conservadores revelam um comportamento mais nítido de recrutamento parlamentar fora das fronteiras partidárias. Tal como na experiência do PFL, seria compreensível que o PSDB produzisse, em sua primeira eleição parlamentar, uma bancada formada, em proporção expressiva, por membros oriundos especialmente do Partido do Movimento Democrático Brasileiro (PMDB), matriz genética de sua constituição. Podese considerar que os $54,1 \%$ de parlamentares puramente tucanos, isto é, sem vínculos anteriores com outras siglas, eleitos em 1990 representam um contingente relevante, indicando uma base a partir da qual o novo partido poderia se constituir e adquirir personalidade própria. Esta base registra ligeiro declínio em 1994, sendo nitidamente deslocada, nas eleições de 1998, por candidatos oriundos de outros partidos.

Os pequenos partidos conservadores expressaram, em sua primeira experiência eleitoral (1986), uma tentativa de investir em identidades bem demarcadas - o Partido Liberal ilustrava, naquele momento, esta estratégia - , movimento que se traduziu no alto percentual de membros exclusivos dentro de suas bancadas. Esta configuração é alterada a partir de 1990, quando a evasão produzida no PMDB e o sucesso do Partido da Reconstrução Nacional (PRN) nas eleições presidenciais de 1989 contribuíram para ampliar a cota dos pequenos, que chega a $18,8 \%$ das cadeiras naquela legislatura. O que se observa desde então é que estas legendas parecem representar menos a expressão de minorias políticas definidas por identidades nítidas do que sublegendas virtuais, disponíveis para o deslocamento contingente, dentro de um espaço de centro-direita. Em 1998, apenas 2 dos 21 parlamentares eleitos por estas pequenas legendas possuíam apenas um registro partidário em seu currículo eleitoral. Mais significativo ainda, os pequenos partidos conservadores apresentam as maiores taxas médias referentes ao número de partidos de seus membros $(2,62)$, sendo que $33,3 \%$ de seus deputados possuem três ou mais filiações anteriores.

Padrão distinto pode ser encontrado nas bancadas do Partido dos Trabalhadores (PT), Partido Democrático Trabalhista (PDT), PMDB e, em graus diferenciados, entre os pequenos partidos de esquerda. Parece previsível que o PT apresente taxas elevadas de recrutamento endógeno entre seus candidatos eleitos para a Câmara dos Deputados, uma vez que o partido valoriza as lealdades firmadas previamente como condição para a mobilidade na carreira. Além disso, seus aspirantes à carreira parlamentar geralmente dispõem de escassos recursos pessoais, dependendo do suporte transferido por estruturas coletivas (partidárias ou de facções).

Neste período, o PMDB formou bancadas com participação significativa de parlamentares projetados exclusivamente a partir de suas fileiras. Característica que parece imune às flutuações observadas no desempenho eleitoral do partido: mesmo em 1986, quando expandiu seu espaço, beneficiando-se do esvaziamento pedessista, mais de $90 \%$ de sua bancada era nativa. Em 1994, o grau de recrutamento endógeno do partido era similar àquele alcançado pelo PT. Porém, a presença de forasteiros ganha um reforço em 1998, invertendo a distribuição observada.

Dentro deste pólo de partidos com bancadas mais homogêneas pode ser localizado, ainda, o PDT, a despeito da inflexão observada neste comportamento. Ao mesmo tempo que diminui sua participação na partilha de cadeiras parlamentares, o trabalhismo apresenta uma gradativa heterogeneidade em sua composição interna, pelo ingresso de candidatos saídos de outras legendas. Já os pequenos partidos de esquerda encobrem fenômenos distintos: enquanto o Partido Comunista do Brasil (PC do B) e o Partido Popular Socialista (PPS) são caracterizados por um recrutamento interno, o Partido Socialista Brasileiro (PSB) apresenta elevada freqüência de integrantes oriundos de outros partidos, fato mais expressivo em sua bancada pernambucana.

O diagnóstico sobre a sedimentação dos vínculos partidários pode ganhar contornos mais precisos quando se agrega ao registro do trânsito interpartidário a informação sobre a direção e a distância da mudança (Gráfico 1).

A migração para partidos de direita ${ }^{6}$ ocorre, de modo bastante acentuado, a partir de uma circulação dentro do mesmo campo ideológico. O que significa que, embora muito intensa, a migra- 
ção para a direita apresenta certa congruência a padrões ideológicos. Em contraste, a mudança para partidos de centro ou de esquerda verifica-se com um trânsito interblocos, através da adesão de políticos egressos de matrizes ideológicas distintas. Parece ocorrer, assim, uma menor freqüência de deslocamentos do centro para a direita, ao lado de movimentos mais freqüentes da direita para o centro e do centro para a esquerda. Não deve passar desapercebido que se em 1986, e mesmo até 1990, o trânsito para o centro obedecia a um procedimento interblocos - a erosão do PDS pode ter contribuído neste sentido - , a partir da composição das legislaturas 1994 e 1998 o currículo dos parlamentares mostra um crescimento de movimentos internos dentro do centro, tendo o PSDB como principal beneficiário. Não chegaria a surpreender que algo próximo à metade de seus deputados já tenha integrado o PMDB, afinal, sua matriz. Por outro lado, o grupo de parlamentares pessedebistas com passagem pelo $\mathrm{PDS} / \mathrm{PPR} / \mathrm{PPB}$ $(19,2 \%)$ e por algum dos pequenos partidos conservadores $(16,2 \%)$ representa um núcleo não desprezível dentro de sua bancada legislativa. Mais ainda, 38 deputados eleitos pelo PSDB em 1998 (correspondendo a 38,4\% de sua bancada) são egressos de partidos conservadores, provenientes sobretudo das regiões Nordeste $(32,7 \%)$, Norte $(26,9 \%)$ e Centro-Oeste $(13,5 \%)$.
Além disto, os dados do Gráfico 1 permitem verificar uma redução na ocorrência agregada de migrações intrablocos, com o decorrente incremento da participação de mudanças ocorridas entre campos ideológicos distintos.

\section{Contrastes estaduais na fidelidade partidária}

A estrutura de oportunidades configurada pelas regras eleitorais surge de imediato como uma explicação promissora para a existência de precários vínculos de lealdade partidária entre os políticos nacionais. Tal perspectiva foi explorada por Mainwaring (1991), ao isolar as conexões entre a regra eleitoral de lista aberta e o incentivo à adoção de estratégias individualistas entre indivíduos que se dedicam à carreira política. Embora pareça evidente que uma oferta partidária elástica, combinada a um procedimento eleitoral que limita a interferência das lideranças partidárias sobre o ordenamento dos candidatos, incentive estratégias individuais desleais, resta a dúvida sobre a extensão em que as regras eleitorais produzem este efeito sobre a classe política brasileira. Assim, dever-se-ia explorar a medida em que o procedimento eleitoral em vigor no Brasil conduz a resultados homogêneos, a despeito da diversidade regional existente. Decompondo os índices de fide-

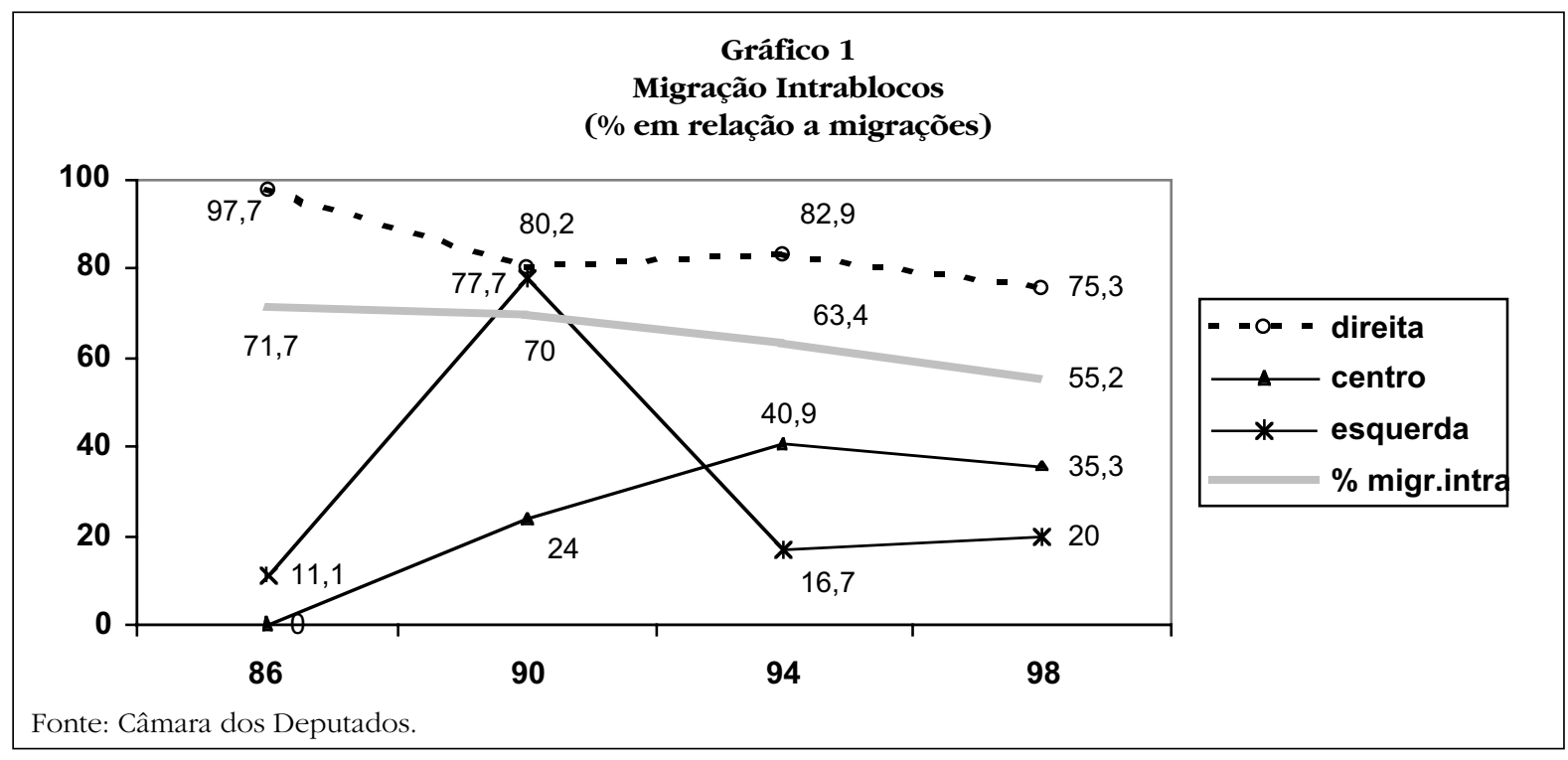


lidade partidária segundo sua expressão em cada estado da Federação, pode-se mensurar as discrepâncias existentes no trânsito interpartidário conforme os diferentes colégios eleitorais (Tabela 3).

Migrações partidárias constituem fenômeno de proporções modestas durante o primeiro ciclo pluripartidário, adquirindo contornos salientes no curso da competição partidária configurada em meados dos anos 80. A despeito de a constituição eleitoral ser basicamente a mesma (fórmula proporcional com lista não ordenada), seu impacto sobre a geração de lealdades partidárias apresenta variações longitudinais e, de forma também significativa, entre as diversas circunscrições eleitorais representadas pelos estados da Federação. Santa Catarina, Rio Grande do Sul e, em escala ligeiramente abaixo, Minas Gerais revelaram uma tendência mais estável quanto aos vínculos partidários. Alagoas e Paraná apresentaram uma dinâmica marcada por movimentos interpartidários expressivos já durante o primeiro sistema pluripartidário e a intensificaram durante o segundo período, fazendo das trocas um comportamento sistêmico em sua competição eleitoral. Em níveis igualmente elevados, embora com expressão limitada ao segundo período, Pernambuco, Maranhão e Bahia elegeram bancadas formadas por políticos com passagem por mais de uma organização partidária. A formação do PFL, com suas principais bases estaduais nestes colégios eleitorais, parece explicar a extensão adquirida pelo fenômeno nestas unidades. Ao considerar toda a extensão da carreira, a freqüência de migrações possui um componente inercial. Um deputado que tenha trocado o PDS pelo PFL em 1985 irá figurar

Tabela 3

Deputados com Filiação Exclusiva

a um Partido, segundo Estados

1950-1962 e 1986-1998

\begin{tabular}{lcccccccc}
\multicolumn{10}{c}{} & \multicolumn{1}{c}{ (em \%) } \\
\hline AC & $\mathbf{1 9 5 0}$ & $\mathbf{1 9 5 4}$ & $\mathbf{1 9 5 8}$ & $\mathbf{1 9 6 2}$ & $\mathbf{1 9 8 6}$ & $\mathbf{1 9 9 0}$ & $\mathbf{1 9 9 4}$ & $\mathbf{1 9 9 8}$ \\
AP & 100 & 100 & 100 & 85,7 & 87,5 & 87,5 & 75,0 & 62,5 \\
AM & - & - & - & - & 50,0 & 87,5 & 50,0 & 25,0 \\
PA & 83,3 & 85,7 & 83,3 & 80,0 & 62,5 & 62,5 & 75,0 & 28,6 \\
RO & 100 & 81,8 & 100 & 100 & 75,0 & 88,2 & 94,1 & 50,0 \\
RR & - & - & - & - & 50,0 & 50,0 & 50,0 & 14,3 \\
TO & - & - & - & - & 75,0 & 75,0 & 87,5 & 11,1 \\
AL & 66,7 & 66,7 & 77,8 & 55,6 & 44,4 & 66,5 & 62,5 & 14,3 \\
BA & 95,5 & 76,0 & 79,2 & 87,5 & 53,8 & 35,9 & 33,3 & 0,0 \\
CE & 93,3 & 89,5 & 73,7 & 90,5 & 60,9 & 72,7 & 72,7 & 30,8 \\
MA & 62,5 & 89,5 & 81,8 & 70,0 & 55,6 & 55,6 & 33,3 & 17,6 \\
PB & 81,8 & 81,8 & 91,7 & 92,3 & 81,8 & 58,3 & 50,0 & 41,7 \\
PE & 72,2 & 86,4 & 81,0 & 92,0 & 48,0 & 32,0 & 16,0 & 20,0 \\
PI & 100 & 85,7 & 71,4 & 100 & 80,0 & 60,0 & 80,0 & 40,0 \\
RN & 85,7 & 85,7 & 100 & 87,5 & 62,5 & 50,0 & 62,5 & 37,5 \\
SE & 100 & 100 & 80,0 & 95,7 & 75,0 & 50,0 & 62,5 & 55,6 \\
DF & - & - & - & - & 100 & 62,5 & 75,0 & 50,0 \\
GO & 71,4 & 75,0 & 100 & 87,5 & 82,4 & 76,5 & 47,1 & 44,4 \\
MT & 100 & 100 & 100 & 100 & 75,0 & 25,0 & 50,0 & 25,0 \\
MS & - & - & - & - & 62,5 & 37,5 & 62,5 & 62,5 \\
ES & 85,7 & 75,0 & 100 & 100 & 80,0 & 50,0 & 50,0 & 30,0 \\
MG & 100 & 95,5 & 95,2 & 95,7 & 84,6 & 66,0 & 66,0 & 50,9 \\
RJ & 87,5 & 82,8 & 78,1 & 82,6 & 78,3 & 67,4 & 67,4 & 36,4 \\
SP & 84,8 & 73,3 & 79,1 & 88,1 & 88,5 & 66,7 & 71,4 & 43,1 \\
PR & 100 & 57,1 & 53,8 & 88,5 & 83,9 & 60,0 & 60,0 & 23,3 \\
SC & 100 & 100 & 100 & 100 & 87,5 & 68,8 & 100 & 68,8 \\
RS & 95,5 & 100 & 96,0 & 100 & 96,8 & 90,3 & 87,1 & 71,0 \\
\hline
\end{tabular}

Fontes: Câmara dos Deputados; Tribunal Supeiror Eleitoral (TSE) e Dicionário bistórico-biográfico brasileiro (FGV-Cpdoc, 1984). 
em qualquer uma das legislaturas em que tenha sido eleito posteriormente na categoria daqueles com mais de uma filiação partidária.

\section{8: migrações e lealdades partidárias}

A composição da Câmara eleita em 1998 se destaca na comparação com as legislaturas anteriores do segundo sistema pluripartidário por apresentar bancadas partidárias mais híbridas quanto à trajetória partidária de seus integrantes. Isolando deputados com filiação exclusiva às legendas responsáveis por sua eleição em 1998, chega-se a um contingente de 40,2\% dos parlamentares, patamar mais baixo neste quesito desde 1982 . O recrutamento de bancadas mais heterogêneas tornou-se particularmente mais saliente no PSDB, PTB, PPB e nos pequenos partidos conservadores. O PFL revela uma reversão na tendência prévia para um recrutamento endógeno gradual, incorporando forasteiros egressos especialmente dos pequenos partidos conservadores.

Esta tendência para o recrutamento de bancadas menos coesas, produzida pelas eleições de 1998, sugere um exame mais detalhado desta legislatura. Não se trata de incorrer em um diagnóstico tentador que consistiria em reiterar a fluidez das fronteiras organizacionais dos partidos brasileiros. Precisamente ao contrário, trata-se de, tomando por referência um contexto de incremento no trânsito interpartidário, apresentar discrepâncias neste fenômeno e isolar os núcleos duros no interior de cada legenda, representados por seções estaduais que preservaram padrões de recrutamento endógenos, em contraste com periferias partidárias, formadas por parlamentares dotados de carreiras políticas constituídas em outras siglas.

Um ganho em informação pode ser obtido quando se vai além do registro de trocas de legenda, buscando analisar a durabilidade dos vínculos partidários a partir da consideração do tempo de filiação partidária do deputado quando da conquista da cadeira parlamentar. A suposição, aqui, é a de que o tempo de filiação oferece evidências acerca das relações firmadas entre aspirantes à carreira parlamentar e cada organização partidária. Valores mais elevados indicam a exigência de uma espécie de estágio probatório como condição para que o candidato a um posto parlamentar possa resgatar o investimento realizado previamente, sob a forma de dedicação às tarefas partidárias, deferência às suas lideranças, progressão na hierarquia da máquina política. Por outro lado, períodos de filiação mais recentes, ou com uma defasagem entre o início da carreira e o vínculo partidário, sugerem a existência de oportunidades franqueadas a novatos no partido, ou, de outra forma, menor capacidade de interferência da organização partidária na seleção de candidatos a uma carreira política.

O procedimento mais adequado para mensurar a continuidade nestes vínculos parece ser o cotejo do tempo de filiação ao partido responsável pela conquista da vaga parlamentar em $1998 \mathrm{com}$ o momento de início da carreira política. Trata-se de identificar se o parlamentar estava filiado ao partido desde o início — ou mesmo antes — de sua carreira política ou, em oposição, se a atual filiação foi firmada em momento mais avançado na sua trajetória pública.

Problema adicional diz respeito ao caso de legendas fundadas durante este período, como o PFL e o PSDB, diante do qual se optou por desprezar a trajetória política anterior à formação destas legendas. Trata-se, assim, de identificar parlamentares com carreiras projetadas fora destas legendas quando estas já haviam sido formadas.

Os valores medianos de cada partido referentes ao tempo de filiação dos seus deputados em relação ao início da carreira são apresentados no Gráfico 2.

O PT apresenta um padrão nítido de recrutamento endógeno: o parlamentar petista mediano filiou-se ao partido seis anos antes do início de sua carreira política. Este parece ser o perfil convencional do partido de militantes, em que o ativismo partidário e a dedicação organizacional representam um capital indispensável para a obtenção de suporte político e recursos eleitorais, como finanças, apoiadores, associação com a imagem e bandeiras partidárias.

PMDB, PFL, PDT e pequenos partidos de esquerda configuram um padrão limite de recruta- 
Gráfico 2

Tempo de Filiação Prévia ao Início da Carreira

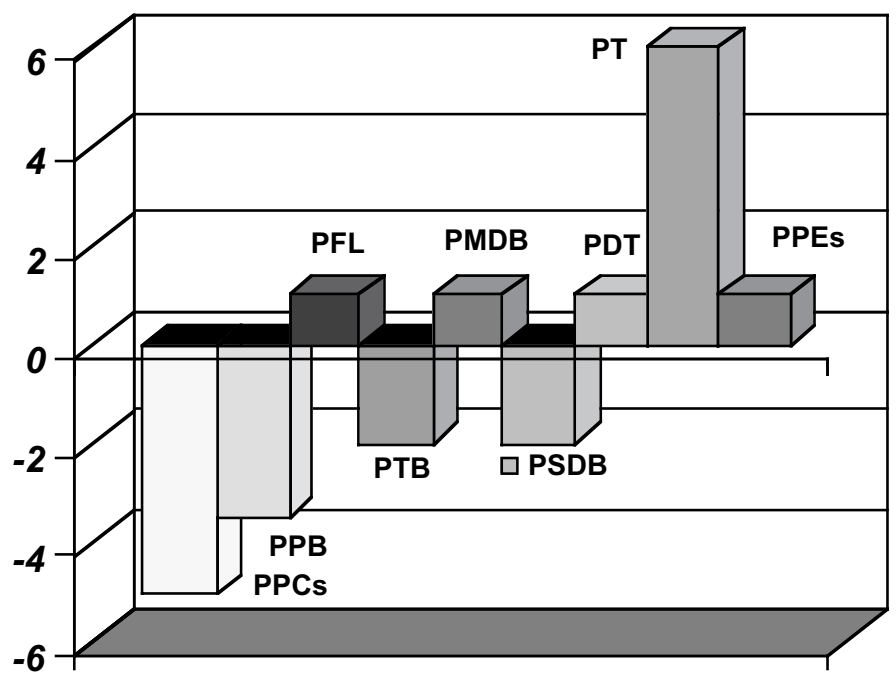

\begin{tabular}{ll}
\hline PPCs & -5 \\
\hline PPB & $-3,5$ \\
\hline PFL & 1 \\
\hline PTB & -2 \\
\hline PMDB & 1 \\
\hline PSDB & -2 \\
\hline PDT & 1 \\
\hline PT & 6 \\
\hline PPEs & 1 \\
\hline
\end{tabular}

mento endógeno. Ingresso na carreira política e filiação partidária ocorrem de forma quase simultânea, sugerindo uma adesão partidária induzida pela ambição de profissionalização política mas, sobretudo, a manutenção posterior dos laços de lealdade partidária originalmente firmados.

Perfil distinto pode ser encontrado quando se examinam as bancadas do PSDB, PTB, PPB e pequenos partidos conservadores. Aqui, a discrepância entre os tempos de filiação e o début na carreira revela lealdades tardias, precedidas por rupturas com identidades políticas iniciais.

A densidade das bancadas partidárias pode ser reconstituída, ainda, através da distribuição dos parlamentares segundo as proporções de seleção endógena (filiação prévia ao início da carreira) ou exógena (filiação posterior ao início da atividade pública), como pode ser examinado no Gráfico 3.

Mais uma vez, o PT de forma mais nítida, mas também o PDT, PMDB, PFL e os pequenos partidos de esquerda revelam uma participação significativa de parlamentares com carreira política projetada dentro dos respectivos partidos. Em contraste, no PSDB, PTB, PPB e PPCs observamos o predomínio de parlamentares que haviam desenvolvido carreiras em outros partidos previamente ao ingresso nas legendas responsáveis por sua eleição nesta legislatura

A sedimentação de organizações partidárias parece estar associada à sua capacidade de exercer um oligopólio sobre a oferta de representação, especialmente mediante o controle sobre as opor- 


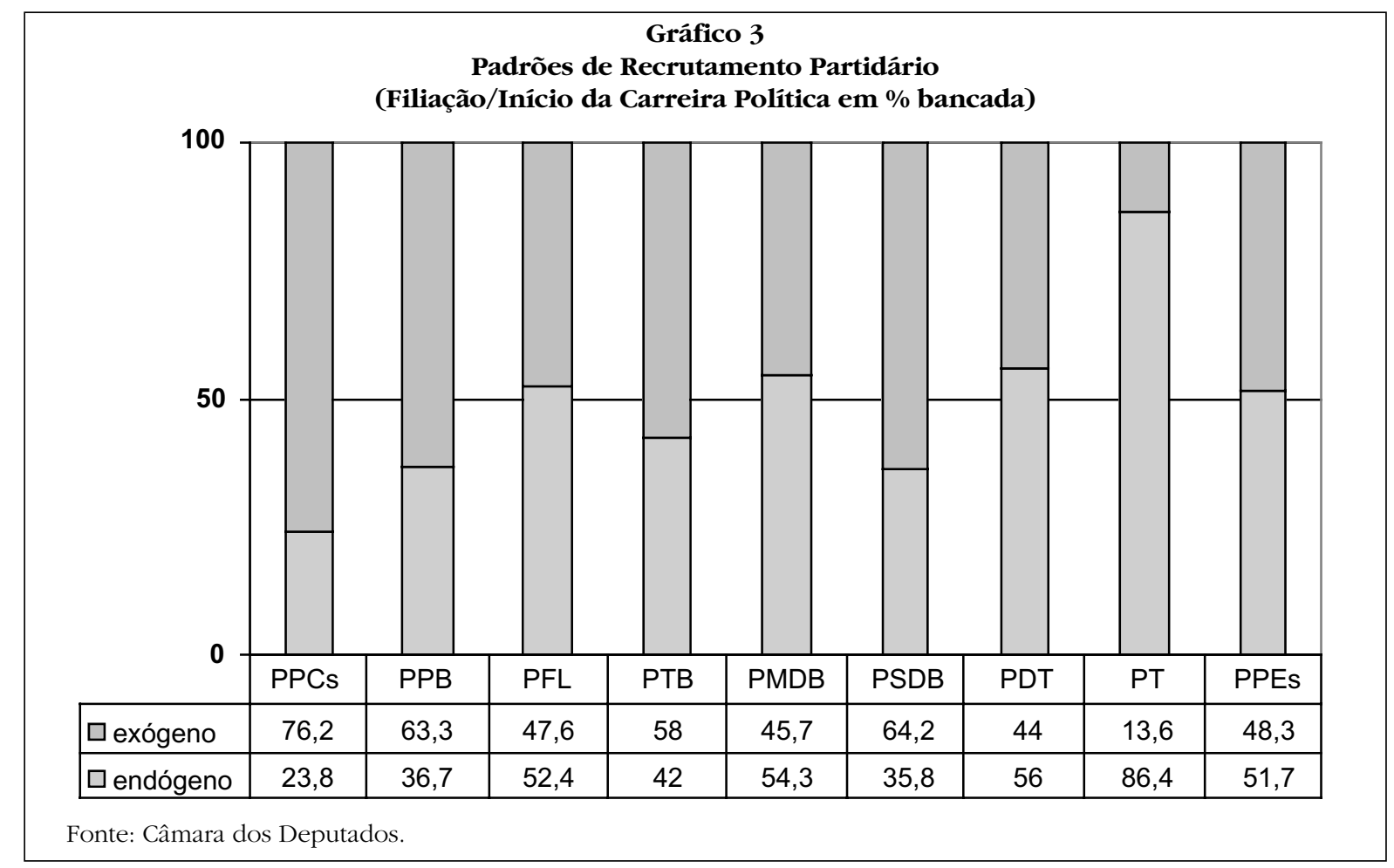

tunidades de ingresso e mobilidade na carreira política. Neste caso, o recrutamento político adquire contornos endógenos, privilegiando a seleção de candidatos previamente testados em anos de dedicação e lealdade ao partido. Deve-se esperar, igualmente, menor competição intrapartidária, uma vez que os custos para o desafio eleitoral podem ser elevados para novatos e a obtenção dos recursos controlados pela organização (finanças, redes de apoios, cabos eleitorais) exige uma deferência confirmada previamente.

Embora seja útil para confirmar diferenças entre as diversas legendas no que diz respeito à sua capacidade de assegurar a lealdade entre seus aderentes, o valor agregado supõe que o comportamento de cada partido seja homogêneo, considerando cada uma de suas bancadas estaduais, subsumindo diferenças que podem ocorrer no plano intrapartidário. Decompondo as legendas segundo suas bancadas estaduais, pode-se visualizar estas diferenças rastreando, dentro de cada organização, as coordenadas de seus núcleos duros, identificados pela expressão de vínculos de lealdade e coesão partidários mais consistentes.
Para proceder a esta operação, cada sigla foi decomposta segundo os índices medianos apresentados por suas bancadas estaduais referentes à relação entre o tempo de filiação partidária e o tempo de carreira política. Índice equivalente a 1 significa uma carreira desenrolada desde seu início sob a mesma legenda partidária. Valores inferiores ou próximos a zero revelam uma defasagem entre o início da carreira e a filiação à legenda responsável por sua eleição nesta legislatura.

Chama a atenção, de imediato, a constituição híbrida dos partidos quando consideramos seus padrões de recrutamento com base neste quesito. As células sombreadas da Tabela 4 destacam bancadas estaduais que apresentam índice equivalente a 1 , constituindo os núcleos duros de cada legenda, configurados por lealdades prévias confirmadas no decorrer da carreira política. PT, PMDB e PFL apresentam maior freqüência de seções estaduais localizadas nestas coordenadas. Merece destaque, igualmente, o fato de que, quando isoladas as seções mais expressivas de cada bancada - aquelas em que sua participação relativa na bancada nacional é superior ao peso do 
estado na Câmara dos Deputados —, 10 das 12 bancadas do PFL e 9 das 11 do PMDB nesta condição apresentam configuração típica de trajetórias leais à legenda.

O PT revela um padrão homogêneo de carreiras políticas projetadas sob a mesma filiação partidária. Entre as seções com recrutamento mais acentuadamente endógeno destacam-se São Paulo e Rio Grande do Sul, estados com maior peso na constituição da bancada petista na Câmara. Prescrutando o perfil dos deputados paulistas, fica evidente o traço de coesão que impregna seus integrantes: 10 dos 14 deputados eleitos em 1998 estavam no partido quando de sua fundação; 3 ingressaram no primeiro ano e o mais recente, em 1986, ainda assim, 6 anos antes de ocupar o primeiro cargo público. Ademais, 11 deputados do PT-SP participaram de sindicatos ou associações por um período médio de 10,4 anos antes da conquista do primeiro cargo e 9 tiveram seu primeiro cargo antes de 1988, revelando a experiência política adquirida em comum desde então. Entre o début na carreira e a entrada na Câmara dos Deputados foram necessários mais 6 anos de percurso, com uma ocupação típica de mais 4 cargos públicos até 1998.

A bancada gaúcha replica, em tons mais amenos, os traços de carreira partidária exibidos pela seção paulista: passagem por postos de direção partidária e atividades sindicais/associativas; intervalo médio de 5,5 anos separando o ingresso na carreira e a conquista do primeiro cargo e de 6,7 anos separando o primeiro cargo da conquista da cadeira na Câmara. Da mesma forma, o número mediano de cargos $(4,0)$ e o grupo que assume seu primeiro cargo antes de 1988 (6) denunciam uma bancada com certa experiência política. Por outro lado, nenhum de seus parlamentares eleitos estava

Tabela 4

Padrões de Recrutamento Partidário, segundo Bancadas Estaduais

\begin{tabular}{|c|c|c|c|c|c|c|c|}
\hline Índice & & & Partido & ancadas esto & ais* & & \\
\hline 1 & \begin{tabular}{ll}
\multicolumn{2}{c}{ PPB } \\
AC & TO \\
SC & PR \\
SE & DF \\
RS & GO \\
ES & BA
\end{tabular} & 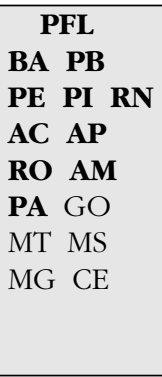 & \begin{tabular}{l}
\multicolumn{1}{c}{ PTB } \\
MT RO \\
PB RS \\
PE MG \\
RJ PA
\end{tabular} & $\begin{array}{l}\text { PMDB } \\
\text { MG RS } \\
\text { CE PB PI } \\
\text { RN GO } \\
\text { MT PA } \\
\text { PE AC } \\
\text { RO MS } \\
\text { RJ SP } \\
\text { PR PA }\end{array}$ & 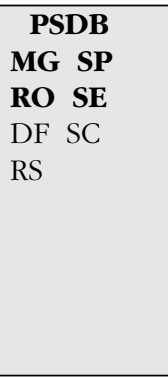 & \begin{tabular}{l}
\multicolumn{1}{c}{ PDT } \\
RJ SC \\
RS AC \\
RR MA \\
MG
\end{tabular} & $\begin{array}{l}\text { PT } \\
\text { SP RS } \\
\text { DF AC } \\
\text { PA BA } \\
\text { MS MG } \\
\text { SC CE } \\
\text { PB PE PI } \\
\text { SE GO } \\
\text { MT ES } \\
\text { RJ PR } \\
\end{array}$ \\
\hline 0.9 & & & SP BA & SC & RJ AM GO & SP & \\
\hline 0.8 & PA CE & PR RJ & & & $\begin{array}{ll}\text { AP } & \text { AL } \\
\text { CE } & \text { MT }\end{array}$ & RO PR & \\
\hline 0.7 & $\begin{array}{l}\text { RR MG } \\
\text { RJ SP }\end{array}$ & SP & PR & $\mathrm{AP}$ DF & $\begin{array}{l}\text { MS ES } \\
\text { TO BA MA }\end{array}$ & $\mathbf{P A}$ & \\
\hline 0.6 & $\mathrm{PE}$ & $\mathrm{DF}$ & & AL BA SE & RR PI & & \\
\hline 0.5 & MS & $\begin{array}{l}\text { MA TO } \\
\text { ES RS }\end{array}$ & MS & MA & PA PB PR & $\mathrm{BA}$ & \\
\hline 0.4 & $\mathbf{A M}$ & SC AL & & ES & & & \\
\hline 0.3 & & & AP ES & & & & \\
\hline 0.2 & $\mathrm{~PB}$ & & RR AL & & & & \\
\hline 0.1 & & & & & & & \\
\hline 0 & $\mathbf{R N}$ & & & RR & & & \\
\hline
\end{tabular}

Índice $=$ tempo de filiação/tempo de carreira.

* Em destaque, as bancadas partidárias estaduais com participação relativa na composição da bancada partidária nacional superior à participação proporcional do colégio estadual na Câmara dos Deputados.

Fonte: Câmara dos Deputados. 
no partido quando de sua fundação, sendo que os mais antigos filiaram-se em 1982, e metade após 1985, sem atravessar, assim, os anos pioneiros de vacas magras do partido no estado. De qualquer forma, o tempo mediano de filiação prévio ao início da carreira ficou em 2 anos, confirmando um padrão endógeno de seleção parlamentar.

Os estados com bancadas dotadas de maior coesão respondem por dois terços da representação do PFL na Câmara. Dentre estes, colégios estaduais em que o partido obteve seu melhor desempenho parlamentar, como Bahia (51,3\%), Piaú (50\%), Amazonas (48,9\%), Pernambuco (37,5\%) e Rio Grande do Norte (37,5\%). A Bahia talvez represente o caso mais expressivo de contenção da disputa em um círculo restrito de candidatos, dotados de trajetórias semelhantes: elegeu 20 dos 26 candidatos apresentados para as 39 vagas estaduais, e ainda com uma moderada taxa de renovação parlamentar (25\%). Entre os eleitos, 10 apresentavam trajetória comum: tendo ingressado na política na legenda da Arena, transferiram-se para o PFL entre 1984 e 1985, permanecendo no partido até $1998 .^{7}$

Situação oposta observa-se nas bancadas pefelistas de estados do Centro-Sul, onde a fragilidade eleitoral do partido é ainda acentuada por um recrutamento franqueado a candidatos sem vínculos duradouros com a legenda. Distintos foram os casos de Tocantins e Maranhão, estados com desempenho parlamentar expressivo, elegendo candidatos com carreiras projetadas em outras siglas.

Alguns dos estados em que o PMDB apresentou melhor rendimento eleitoral foram também caracterizados por bancadas coesas: Goiás, Paraíba, Piauí, Rio Grande do Norte, Mato Grosso, Minas Gerais e Rio Grande do Sul. A seção gaúcha do PMDB deve ser destacada pela homogeneidade na seleção de seus aspirantes a parlamentares: a maioria estava filiada ao partido desde 1982, com um caso de filiação posterior, após o início da carreira (Nelson Proença). Parece oportuno, também, chamar a atenção para a bancada paulista do PMDB. Datas de filiação indicam um padrão anterior ao início da carreira; contudo, parece evidente uma tendência de declínio eleitoral, com a sigla tendo atingido sua performance mais modesta no estado desde a fundação partidária.
Um pouco mais rarefeita parece ser a configuração do PSDB. Apenas 7 bancadas estaduais enquadraram-se nos requisitos oferecidos como indicadores de seleção endógena e coesão partidária. Mais revelador ainda, 17 bancadas estaduais apresentaram um padrão de filiações posteriores ao ingresso na carreira política, com adesões efetuadas especialmente após 1994, quando o partido conquista os governos federal e de estados importantes. Dentre estas, bancadas importantes como as do Ceará, Pará e Rio de Janeiro.

PPB e PTB possuem menor número de bancadas definidas por um padrão de controle partidário sobre o recrutamento parlamentar. A bancada paulista do PPB, responsável por 20\% dos deputados eleitos pelo partido em 1998, é formada por deputados com adesão recente: dos 12 deputados eleitos, apenas 2 (Cunha Bueno e Delfim Netto) estão no partido desde sua fundação mais remota, 10 filiaram-se depois de $1993^{8}$ e metade filiou-se após 1995, a maioria tendo migrado do PMDB a partir do final do governo Fleury. O peso das bancadas duras do PTB em relação ao conjunto de sua bancada é minoritário. Os estados mais importantes na constituição de sua representação nacional, como Paraná e Espírito Santo, apresentam bancadas formadas quase inteiramente por candidatos com carreiras prévias antes do registro partidário pelo PTB. ${ }^{9}$

\section{Fecho}

Ensaiando um mínimo denominador operacional capaz de enquadrar conceitualmente organizações partidárias, Sartori (1982, p. 86) sugeriu que seu traço peculiar, que as distingue de outras estruturas similares, é o de um grupo político que se apresente em eleições, e seja capaz de colocar, através de eleições, candidatos a cargos públicos. Partidos são colocados à prova de modo mais severo quando perdem o controle sobre a seleção de candidatos ao ingresso ou continuidade em uma carreira política. A fisionomia organizativa de cada agremiação parece configurada pelo domínio que sua liderança exerce sobre áreas de incerteza (Panebianco, 1990), que afetam a estabilidade da organização, como a estrutura de oportunidades para carreiras políticas. 
Um rastreamento das organizações partidárias brasileiras permite-nos perceber sua consistência distinta ao longo dos dois ciclos competitivos. Entre 1946 e 1962, a despeito das tendências à dispersão, provocadas pelo voto dos eleitores, e à desagregação no comportamento decisório legislativo, as organizações partidárias preservaram fronteiras estáveis, como fica evidente na dimensão marginal do trânsito interpartidário. Distinta parece ser a consistência das organizações produzidas durante o segundo sistema pluripartidário, resultado de um incremento no trânsito verificado entre as legendas. Contudo, os dados apresentados neste artigo sugerem prudência em relação ao tratamento uniforme conferido às organizações partidárias brasileiras. Variações entre as diferentes legendas e no seu interior, entre cada bancada estadual, não devem ser desprezadas. Partidos apresentam uma configuração bíbrida quanto a trajetórias e vínculos de lealdade de seus membros. Dentro de cada um convivem, em proporções que variam segundo cada caso, núcleos duros, seções estaduais formadas por parlamentares com carreiras projetadas sob a mesma legenda, ao lado de periferias partidárias, compostas por fluxos de filiações tardias.

Migração e lealdade partidárias constituem fenômenos cuja explicação não parece residir em variáveis demográficas. Não se trata de encontrar identidades estáveis nos centros modernos e urbanos, em contraposição à infidelidade e personalismo supostamente presentes nos colégios estaduais rurais. No PFL, por exemplo, são justamente suas bancadas nordestinas que apresentam vínculos de lealdade mais duráveis, enquanto suas bancadas do Centro-Sul são formadas em maior proporção por egressos de outras siglas.

Tampouco parece satisfatória, diante da complexidade deste fenômeno, uma explicação que busque nas regras eleitorais, em especial no procedimento de lista aberta, a causa para a adoção de estratégias não leais. Embora se deva reconhecer que um ordenamento da lista promovido pela votação nominal de cada candidato possa incentivar migrações, parece necessário considerar que seus efeitos não são lineares, sendo refratados por tradições, lideranças e padrões de competição registrados em cada contexto.

\section{NOTAS}

1 Os dados referem-se à vida política de cada deputado em toda a sua extensão, e não apenas aos movimentos verificados durante o mandato na Câmara dos Deputados.

2 Pequenos partidos conservadores: compreende as legendas com este perfil ideológico e menos de 5\% da representação na Câmara dos Deputados durante o período: PR, PDC, PL e PRP.

3 Pequenos partidos progressistas: compreende as legendas com este perfil e menos de $5 \%$ da representação na Câmara dos Deputados durante o período: PSB, PTN, PST, PRT, MTR E PCB.

4 Pequenos partidos conservadores: compreende legendas com este perfil ideológico e menos de $5 \%$ da representação na Câmara dos Deputados durante o período: PL, PRN, PDC, PSC, PSD, PMN, PRS, PST, PTR, PRONA, PSL E PRP.

5 Pequenos partidos de esquerda: compreende legendas com este perfil ideológico e menos de $5 \%$ de assentos na Câmara durante o período: PSB, PC do B, PPS/PCB, PV e PSTU.

6 Os partidos foram assim enquadrados: Direita (PDS/ PPR/PPB, PFL, PTB, PRN, PL, PDC, PSC, PRS, PTR, PP, PST, PMN, PSD, PRP, PRONA e PSL), Centro (PMDB e PSDB) e Esquerda (PT, PDT, PSB, PCB/PPS, PC do B, PV e PSTU).

7 Benito Gama, Eraldo Tinoco, Jairo Carneiro, Jorge Khoury, José Rocha, José Ronaldo, Leur Lomanto, Manoel Castro, Paulo Braga e Ursicino Queiroz. Ver Câmara dos Deputados (1999).

8 O que não deve ser confundido com o evento de fundação do PPR, a partir da fusão PDS-PDC. Na verdade, estes deputados não chegaram a integrar nenhuma destas siglas, filiando-se somente após a fundação de seu sucedâneo.

9 A única exceção nestes dois estados é o deputado Alex Canziani, filiado desde 1987, um ano antes de ocupar seu primeiro cargo público, como vereador em Londrina.

\section{BIBLIOGRAFIA}

BOTTINELLI, Oscar. (1993), "El parlamento y su función política". Cuadernos del Claeh, Montevidéu, $73 / 74$.

BOWLER, Shaun, FARRELL, David e KATZ, Richard. (1999), "Party cohesion, party discipline and parliaments", in S. Bowler, D. Farrell e R. Katz, Party discipline and parliamentary government, Ohio State University. 
CÂMARA DOS DEPUTADOS. (1981), Deputados brasileiros (1946-1967). Coord. David Fleischer. Brasília, Coordenação de Publicações.

(1984), Deputados brasileiros. Repertório biográfico dos membros da $47^{a}$ legislatura (1983-1987). 2 a ed., Brasília, Coordenação de Publicações.

(1987), Deputados brasileiros. Repertório biográfico dos membros da Assembléia Nacional Constituinte. Brasília, Coordenação de Publicações.

(1991), Deputados brasileiros. Repertório biográfico dos membros da $49^{a}$ legislatura (1991-1995). Brasília, Coordenação de Publicações.

. (1995), Deputados brasileiros. Repertório biográfico dos membros da $50^{\text {a }}$ legislatura (1995-1999). Brasília, Coordenação de Publicações.

(1999), Deputados brasileiros. Repertório biográfico dos membros da 51a legislatura (1999-2003). Brasília, Coordenação de Publicações.

DIAP — DEPARTAMENTO INTERSINDICAL DE ASSESSORIA PARLAMENTAR. (1988), Quem foi quem na Constituinte nas questões de interesse dos trabalhadores. São Paulo, Oboré/Cortez.

FGV-CPDOC. (1984), Dicionário histórico-biográfico brasileiro (1930-1983). Coord. Israel Beloch e Alzira Alves de Abreu. Rio de Janeiro, Forense.

FIGUEIREDO, Argelina e LIMONGI, Fernando. (1995), Terra incógnita: funcionamento e perspectivas do Congresso Nacional. Relatório de pesquisa. São Paulo, Cebrap, janeiro.

(1999), Executivo e Legislativo na nova ordem constitucional. São Paulo, Ed. da FGV.

GONZALEZ, Luis Eduardo. (1993), Estructuras politicas y democracia en el Uruguay. Montevidéu, Fundación de Cultura Univeritária.

LAVAREDA, Antônio. (1991), A democracia nas urnas: o processo partidário eleitoral brasileiro. Rio de Janeiro, Rio Fundo/Iuperj.

LIMA JR., Olavo Brasil. (1983), Partidos politicos brasileiros. A experiência federal e regional: 1945/ 64. Rio de Janeiro, Graal.
MAINWARING, Scott. (1991), "Políticos, partidos e sistemas eleitorais: o Brasil numa perspectiva comparada”. Novos Estudos Cebrap, São Paulo, 29, março.

(1999), Rethinking party systems in the third wave of democratization. The case of Brazil. Stanford, Stanford University Press.

MAINWARING, Scott e LIÑAN, Aníbal Pérez. (1998), "Disciplina partidária: o caso da Constituinte". Lua Nova, São Paulo, 44.

MENEGUELLO, Rachel. (1998), Partidos e governo no Brasil contemporâneo. (1985-1997). São Paulo, Paz e Terra.

NICOLAU, Jairo. (1996), Multipartidarismo e democracia. Um estudo sobre o sistema partidário brasileiro (1985-94). Rio de Janeiro, Ed. da FGV.

PANEBIANCO, Ângelo. (1990), Modelos de partidos. Organización y poder en los partidos politicos. Madri, Alianza.

RODRIGUES, Leôncio Martins. (1987), Quem é quem na Constituinte. Uma análise sociobiográfica dos partidos e deputados. São Paulo, O Estado de São Paulo/Maltese.

SARTORI, Giovanni. (1982), Partidos e sistemas partidários. Brasília, Ed. da UnB.

SCHMITT, Rogério. (1999), "Migração partidária e reeleição na Câmara dos Deputados". Novos Estudos Cebrap, São Paulo, 54, julho.

SCHWARTZMAN, Simon. (1988), Bases do autoritarismo brasileiro. Rio de Janeiro, Campus.

SOARES, Gláucio Dillon. (1973), Sociedade e política no Brasil. São Paulo, Difel. 